\title{
Optimizing the spontaneous-emission B factor for single optical plasmon generation
}

\author{
Chen, Yuntian; Nielsen, Torben Roland; Gregersen, Niels; Lodahl, Peter; Mørk, Jesper
}

Published in:

Proceedings, CLEO/Europe - EQEC

Link to article, DOI:

10.1109/CLEOE-EQEC.2009.5192257

Publication date:

2009

Document Version

Publisher's PDF, also known as Version of record

Link back to DTU Orbit

Citation (APA):

Chen, Y., Nielsen, T. R., Gregersen, N., Lodahl, P., \& Mørk, J. (2009). Optimizing the spontaneous-emission B factor for single optical plasmon generation. In Proceedings, CLEO/Europe - EQEC (pp. 1-1). IEEE.

https://doi.org/10.1109/CLEOE-EQEC.2009.5192257

\section{General rights}

Copyright and moral rights for the publications made accessible in the public portal are retained by the authors and/or other copyright owners and it is a condition of accessing publications that users recognise and abide by the legal requirements associated with these rights.

- Users may download and print one copy of any publication from the public portal for the purpose of private study or research.

- You may not further distribute the material or use it for any profit-making activity or commercial gain

- You may freely distribute the URL identifying the publication in the public portal 


\title{
Optimizing the spontaneous-emission $\beta$ factor for single optical plasmon generation
}

\author{
Yuntian Chen, Torben Roland Nielsen, Niels Gregersen, Peter Lodahl, and Jesper Mørk \\ DTU Fotonik, Department of Photonics Engineering, Ørsteds Plads, Building 343v, DK-2800 Kgs. Lyngby, Denmark
}

In applications like quantum cryptography and quantum computation, it is desirable to obtain single photon sources which can produce a train of single photons on demand at a high repetition rate, especially at or near room temperature. Such single-photon sources can be realized by tailoring the photonic environment of the quantum emitter. The photonic environment determines the local density of states, into which the photon can be emitted. A number of structures such as interfaces, cavities and waveguides have already been used to modify the spontaneous emission (SE) rate; nevertheless there is still room for improving the overall efficiency of the single-photon sources, e.g., by inventing new ways of enhancing light-matter interaction.

Recently it has been proposed and experimentally demonstrated that a quantum emitter can be coupled to surface plasmon polaritons (SPP) [1-3]. Inspired by these ideas, we analyze a simple configuration for generating optical plasmon excitations that can be coupled out afterwards as efficient single photons. The quantum emitter is subjected to multiple decay channels, namely the radiative decay channel, the non-radiative decay channel, and the SPP decay channel. We search here for parameters in order to optimize the SE $\beta$ factor, which is the fraction of the SE coupled into a single SPP mode and is the figure of merit of the single-photon source efficiency. Our setup is similar to Ref. [3], which focused on the decay rate into the SPP channel, whereas we target the SE $\beta$ factor for one plasmonic mode by calculating both the SPP decay rate and the total decay rate numerically.
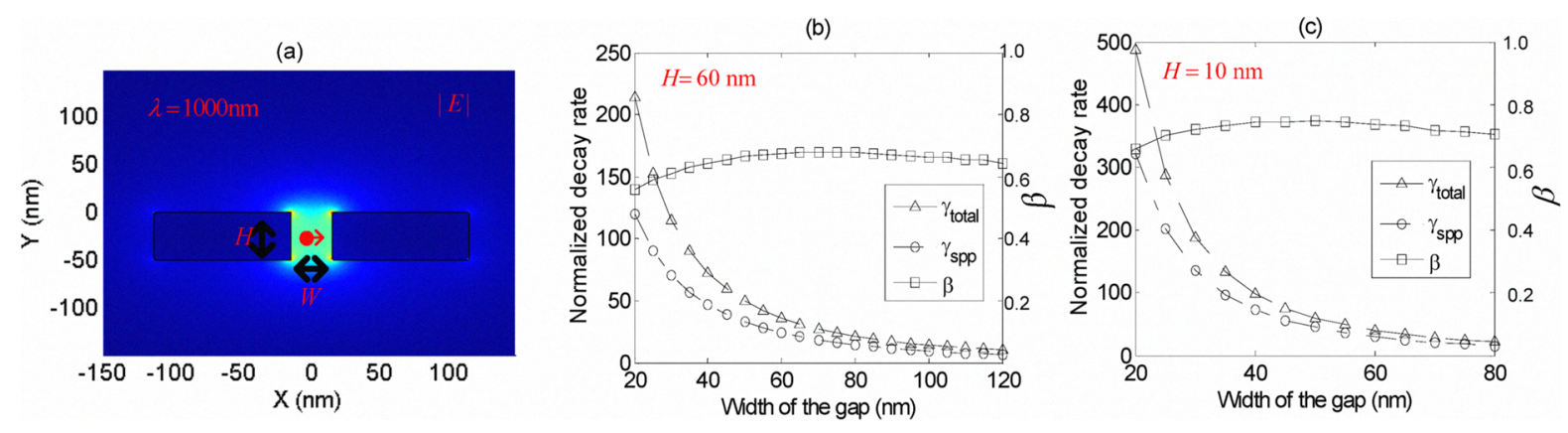

Fig. 1 (a) Schematics of an emitter coupled to a gap plasmon waveguide. $\varepsilon_{\text {gold }}=-46.441+3.505 i, \varepsilon_{\text {air }}=1$ (b) Gap width dependence of the decay rates and $\beta$ factor when the height of the metallic structure is $60 \mathrm{~nm}$. The SE decay rate is normalized to the rate in vacuum (c) Gap width dependence of the decay rates and $\beta$ factor when the height of the metallic structure is $10 \mathrm{~nm}$

We study the metallic waveguide, consisting of two gold strips surrounded by air, at the wavelength of 1000 nm, see Fig. 1 (a). With the typical size of widths and heights illustrated in Fig. 1 (a), such structures can support two plasmonic modes, one with E-field concentrated in the gap (gap mode) and one with E-field concentrated at the corners outside the gap (separated mode). The emitter is positioned in the middle of the gap with a dipole oriented horizontally. In this case the gap mode will dominate while the separated mode will be suppressed. We study the influence of the width of the gap $(W)$ and the height of the metallic strips $(H)$ on the SE $\beta$ factor for the gap mode, given as the SE decay rate coupled to the gap mode $\gamma_{s p p}$ divided by the total decay rate $\gamma_{\text {total }}$. The SPP decay rate is obtained by solving the wave equation in a 2D model [4], which takes advantage of the translation symmetry along the z-axis. The total decay rate is extracted by solving the full set of Maxwell equations with a current source using a 3D finite element method. Based on our numerical model we find that with a success probability up to $75 \%$ single optical plasmons can be generated when the quantum emitter decays.

\section{References}

[1] D. E. Chang, A. S. Sørensen, P. R. Hemmer, and M. D. Lukin, 'Quantum Optics with Surface Plasmons," Phys. Rev. Lett. 97,053002 (2006).

[2] A. V. Akimov, A. Mukherjee, C. L. Yu, D. E. Chang, A. S. Zibrov, P. R. Hemmer, H. Park, and M. D. Lukin, "Generation of single optical plasmons in metallic nanowires coupled to quantum dots," Nature 450, 402(2007)

[3] Y. C. Jun, R. D. Kekatpure, J. S. White, and M. L. Brogersma, "Nonresonant enhancement of spontaneous emission in metal-dielectricmetal plasmon waveguide structures" Phys. Rev. B. 78, 153111 (2008).

[4] T. Søndergaard and S. I. Bozhevolnyi, ’'Surface plasmon polariton scattering by a small particle placed near a metal surface: An analytical study," Phys. Rev. B. 69, 045422 (2004). 